\title{
Deep reactive ion etching of silicon carbide
}

\author{
S. Tanaka ${ }^{a}$ \\ Department of Mechatronics and Precision Engineering, Tohoku University, 01 Aza Aoba, Aramaki, \\ Aoba-ku, Sendai 980-8579, Japan \\ K. Rajanna \\ Department of Instrumentation, Indian Institute of Science, Bangalore-560 012, India \\ T. Abe \\ Department of Mechatronics and Precision Engineering, Tohoku University, 01 Aza Aoba, Aramaki, \\ Aoba-ku, Sendai 980-8579, Japan \\ M. Esashi \\ New Industry Creation Hatchery Center, Tohoku University, 01 Aza-Aoba, Aramaki, Aoba-ku, \\ Sendai 980-8579, Japan
}

In this article, we describe more than 100- $\mu$ m-deep reactive ion etching (RIE) of silicon carbide $(\mathrm{SiC})$ in oxygen-added sulfur hexafluoride $\left(\mathrm{SF}_{6}\right)$ plasma. We used a homemade magnetically enhanced, inductively coupled plasma reactive ion etcher (ME-ICP-RIE) and electroplated nickel masks. First, $5 \mathrm{~h}$ etching experiments using etching gases with $0 \%, 5 \%, 10 \%$ and $20 \%$ oxygen were performed by supplying rf power of 150 and $130 \mathrm{~W}$ to an ICP antenna and a sample stage, respectively. They demonstrated a maximum etch rate of $0.45 \mu \mathrm{m} / \mathrm{min}$ and residue-free etching in the case of 5\% oxygen addition. Observation of the cross sections of etched samples using a scanning electron microscope confirmed a microloading effect, which is reduction of the etched depth with a decrease in the mask opening width. Next, a $7 \mathrm{~h}$ etching experiment using an etching gas with $5 \%$ oxygen was performed by increasing the rf power to the sample stage to $150 \mathrm{~W}$. This yielded an etched depth of $216 \mu \mathrm{m}$.

\section{INTRODUCTION}

Silicon carbide $(\mathrm{SiC})$ is a promising material for high temperature, high power, high voltage and high frequency semiconductor devices because of its large band gap, large thermal conductivity, high breakdown voltage and high saturated electron velocity. $\mathrm{SiC}$ is also an excellent structural material which is used in harsh environments, where it would be exposed to high temperature, erosive atmospheres or friction, because of its high thermal resistivity, high hardness, chemical inertness and high wear resistivity. In microelectromechanical systems (MEMS), the latter advantages find use in pressure sensors, ${ }^{1}$ bolometers, ${ }^{2}$ a microresonator, ${ }^{3,4}$ microgear, ${ }^{3}$ micromotors, ${ }^{5}$ fuel atomizers, ${ }^{6}$ micromachined gas turbine rotors ${ }^{7}$ and so on.

For micromachining of $\mathrm{SiC}$, lost molding, ${ }^{3,6,7}$ reactive ion etching (RIE) $)^{8-16}$ and laser-assisted photoelectrochemical etching ${ }^{17,18}$ have been used. Yasseen et $\mathrm{ll}^{3}{ }^{3}$ fabricated a $\mathrm{SiC}$ microresonator and microgear by removing a silicon dioxide sacrificial layer on a silicon substrate after coating the substrate with a $\mathrm{SiC}$ film by chemical vapor deposition (CVD). Rajan et al. ${ }^{6}$ fabricated a $\mathrm{SiC}$ fuel atomizer for jet engines by etching away a silicon mold, which was microfabricated by deep RIE, after coating the mold with a thick $\mathrm{SiC}$ layer by CVD. Tanaka et al. ${ }^{7}$ fabricated a $\mathrm{SiC}$ micromachined gas turbine rotor with a diameter of $5 \mathrm{~mm}$ by reaction sintering material power containing $\mathrm{SiC}$ and graphite by hot isostatic

${ }^{a}$ Electronic mail: shuji@cc.mech.tohoku.ac.jp pressing (HIP) after filling silicon molds with the material powder. These silicon lost molding techniques can produce relatively thick $\mathrm{SiC}$ microstructures with thickness of over several hundred microns.

The RIE of $\mathrm{SiC}$ is mainly applied to thin films. In previous studies ${ }^{8-16}$ used $\mathrm{SF}_{6}, \mathrm{CF}_{4}, \mathrm{NF}_{3}, \mathrm{CHF}_{3}$ or $\mathrm{CBrF}_{3}$ mixed with oxygen was used as an etching gas. The etch rate is generally several tens of $\mathrm{nm} / \mathrm{min}$ or less, which is much smaller than that of silicon, however, high etch rates of about $1 \mu \mathrm{m} / \mathrm{min}$ were also reported. ${ }^{14,16}$ In the previous studies, etched depth of below $10 \mu \mathrm{m}$ using $\mathrm{SiC}$ thin films prepared by CVD was achieved. In this article, we report the deep RIE of $\mathrm{SiC}$ with depth of more than $100 \mu \mathrm{m}$ for MEMS used in harsh environments such as for microcombustors and microheat engines.

\section{EXPERIMENTS}

\section{A. Deep RIE system}

We used a homemade magnetically enhanced, inductively coupled plasma reactive ion etcher (ME-ICP-RIE). ${ }^{19}$ The ME-ICP-RIE has a single turn ICP coil (ICP antenna) and a samarium-cobalt $(\mathrm{Sm}-\mathrm{Co})$ permanent magnet to generate high density plasma. The ICP antenna surrounding the magnet is installed on a quartz glass cover for a $\phi 200 \mathrm{~mm}$ process chamber. The process chamber, which has a small volume of about $1 \times 10^{-3} \mathrm{~m}^{3}$, is pumped using a turbomolecular pump (TMP) with a large capacity of 200 1/s. 
(0) $\mathrm{SiC}$ wafer preparation

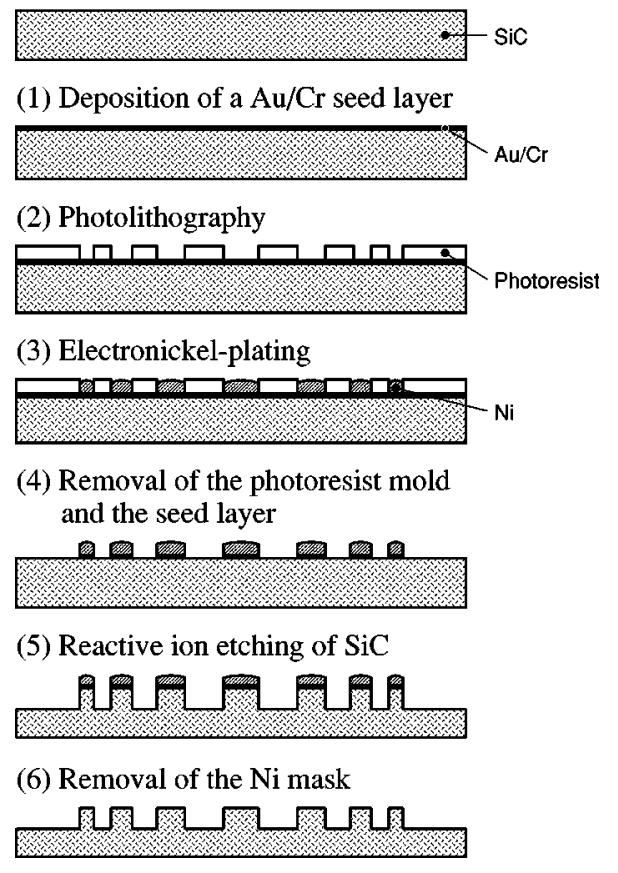

FIG. 1. Experimental process for deep RIE of SiC.

This prevents reaction products from redepositing on an etched substrate. An aluminum alloy sample stage with a diameter of $80 \mathrm{~mm}$ is cooled by coolant without water (GALDEN, Ausimont) to prevent electrical leakage through the coolant. In our experiments, the stage temperature was held constant at $20^{\circ} \mathrm{C}$. Samples were attached to the stage with silicone grease for thermal conductivity. The distance between the stage and the quartz glass cover is $13 \mathrm{~mm}$.

Plasma was generated by supplying $13.56 \mathrm{MHz}$ rf power to both the ICP antenna and the sample stage. In our experiments, a rf power of $150 \mathrm{~W}$ was supplied to the ICP antenna, and that of 130 or $150 \mathrm{~W}$ was supplied to the sample stage. $\mathrm{Rf}$ power of 130 and $150 \mathrm{~W}$ to the stage generated self-bias voltages of -420 and $-480 \mathrm{~V}$, respectively. As an etching gas, sulfur hexafluoride $\left(\mathrm{SF}_{6}\right)$ mixed with oxygen was used. The total gas flow and oxygen concentrations of $0 \%, 5 \%$, $10 \%$, and $20 \%$ were controlled by mass flow controllers, so that the pressure of the process chamber became $0.24 \mathrm{~Pa}$. This pressure is the minimum necessary for stable plasma generation, and helps to prevent reaction products from redepositing on an etched substrate. The etching gas was supplied to the process chamber from an annular gas inlet surrounding the sample stage for uniform etching.

\section{B. Experimental process}

We used sintered SiC substrates (Nihon Ceratec) for deep RIE experiments. These substrates have a purity of $99.1 \%$, and contain $0.7 \%$ free carbon as well as small amounts of boron, aluminum, iron, calcium and other impurities. The surface of the substrates was polished to a mirror finish. Figure 1 illustrates the experimental process. This process was used by Wang et al. ${ }^{20}$ and by Li et $a l^{21}$ for the deep RIE of

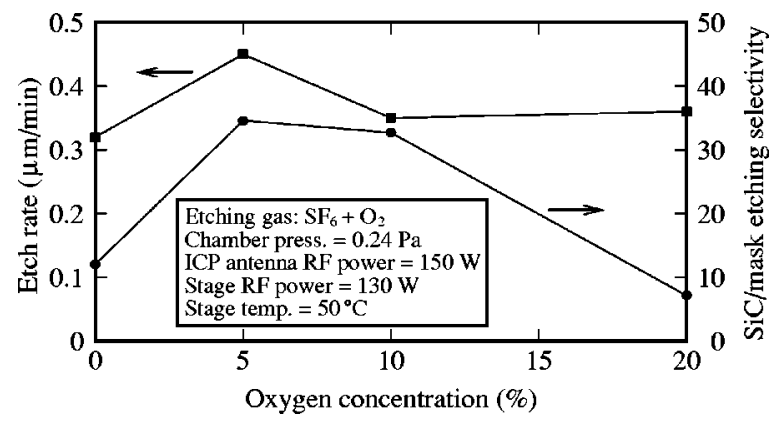

FIG. 2. Etch rate and $\mathrm{SiC}$ etching selectivity to the Ni mask as functions of the oxygen concentration in the etching gas. (a) No oxygen. (b) $5 \%$ oxygen.

lead zirconate titanate (PZT) and Pyrex glass, respectively. First, a gold/chromium seed layer for electroplating was deposited on the cleaned substrate by sputtering and, subsequently, a photoresist film (AZP4903, Clairant) with a thickness of $14 \mu \mathrm{m}$ was spun on and patterned by photolithography.

Next, a mold formed by the photoresist film was filled with nickel (Ni) by pulse electroplating. For electroplating, we used a Ni sulfamate bath and a pulsed current with a density of $25 \mathrm{~mA} / \mathrm{cm}^{2}$ and a duty ratio of $1: 1$. The deposition rate was several $\mu \mathrm{m} / \mathrm{h}$ in most cases, but significantly depended on the conditions of the solution. Finally, the substrate was ready for deep RIE after the removal of the photoresist film and the seed layer. $1 \mathrm{~h}$ RIE steps were performed, each of which was followed by measurement of the etched depths using a stylus-type surface profiler. After all RIE steps were finished, the substrate was cut using a dicing saw to observe its cross section using a scanning electron microscope (SEM).

\section{RESULTS AND DISCUSSION}

As has been reported in many papers ${ }^{8-16}$ for the RIE of $\mathrm{SiC}$, a fluorinated etching gas was mixed with oxygen to increase the etch rate and to reduce residue. The tendency of an increase in etch rate by oxygen addition can be explained partly by the promotion of a fluorine generation reaction between $\mathrm{SF}_{n}$ radicals and oxygen ${ }^{22}$, and partly by the promotion of carbon removal in forms such as carbon mono- and dioxide. ${ }^{9}$ Figure 2 shows etching rates and $\mathrm{SiC}$ etching selectivities to the Ni mask in the cases of $0 \%, 5 \%, 10 \%$ and $20 \%$ oxygen addition. Rf power of 150 and $130 \mathrm{~W}$ was supplied to the ICP antenna and the sample stage, respectively. The total etching time was $5 \mathrm{~h}$.

The etch rate showed a maximum value of $0.45 \mu \mathrm{m} / \mathrm{min}$ in the case of $5 \%$ oxygen addition. More or less oxygen addition resulted in reduction of the etch rate and the deposition of a grass-like residue on the etched bottom surfaces. Figures 3(a) and 3(b) show the cross-sectional SEM images of samples etched for $5 \mathrm{~h}$ in the cases of $0 \%$ and $5 \%$ oxygen additions, respectively. The former has no residue on the etched bottom surface, whereas the latter has a grass-like residue. Samples etched in the cases of $10 \%$ and $20 \%$ oxygen addition also have a grass-like residue similar to that 


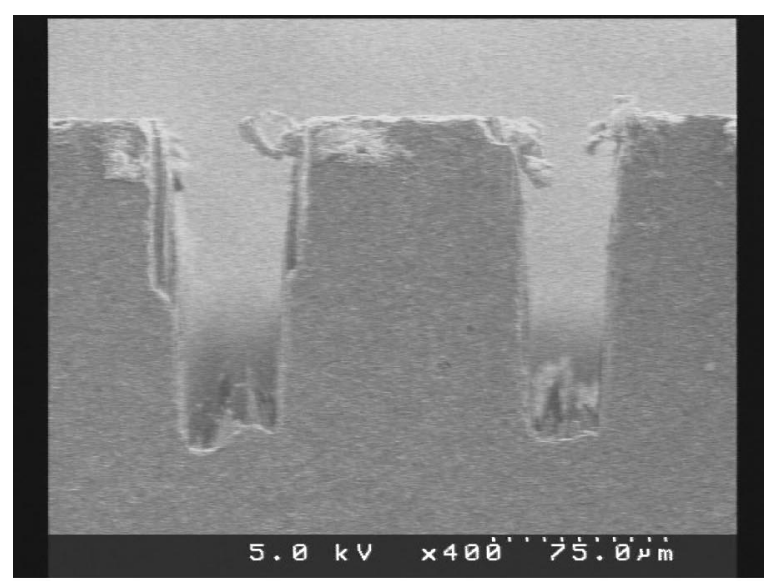

(a) No oxygen.

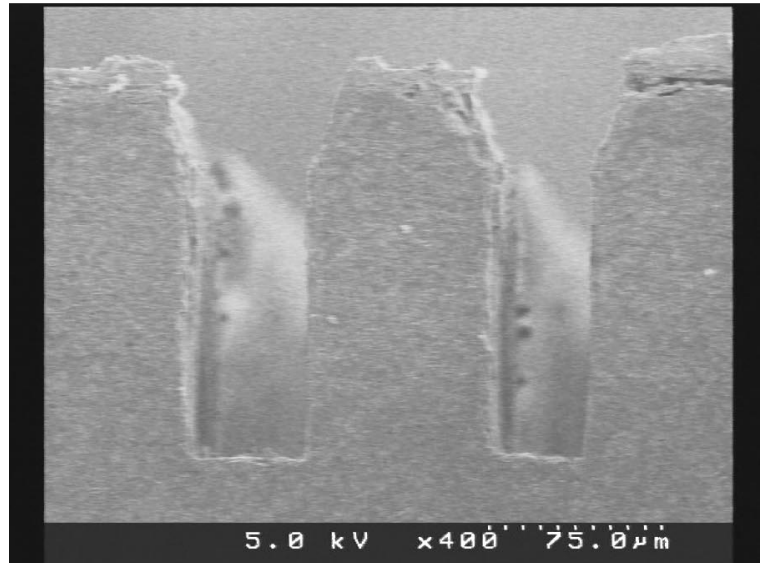

(b) $5 \%$ oxygen

FIG. 3. Cross-sectional SEM images of a sample etched for $5 \mathrm{~h}$.

shown in Fig. 3(a). This reason could be that less oxygen leads to the formation of a carbon passivation layer, whereas excess oxygen results in the redeposition of metals from the mask and the sample stage, whose erosion could be enhanced by an increase in oxygen. The $\mathrm{SiC}$ etching selectivity to the $\mathrm{Ni}$ mask showed a maximum value of 35 also in the case of $5 \%$ oxygen addition.

Figure 4 shows the relationships between the opening widths of a grating mask and the etched depths. This con-

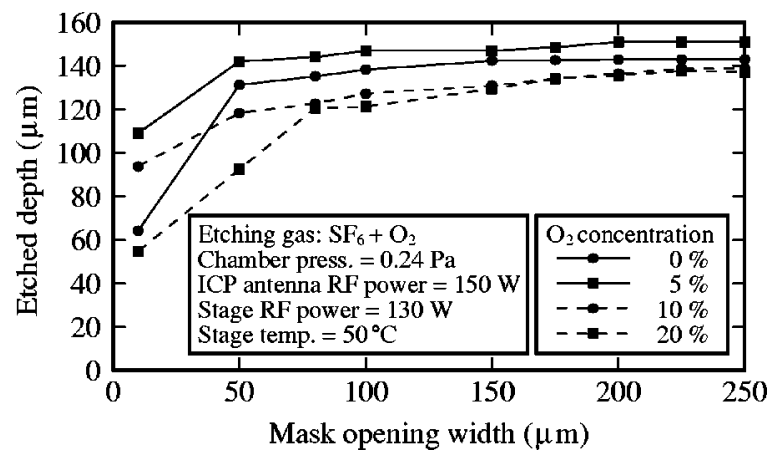

FIG. 4. Relationships between the mask opening width and the etched depth after $5 \mathrm{~h}$ etching.

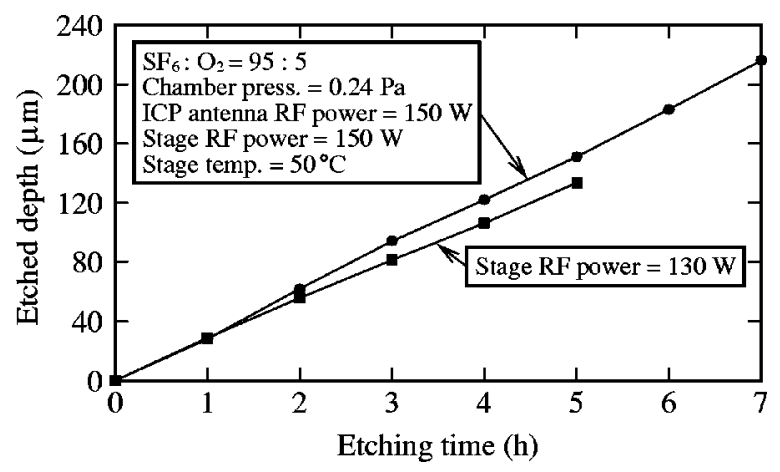

FIG. 5. Relationships between the etching time and the etched depth.

firms the microloading effect, which is reduction of the etched depth with a decrease in the mask opening width. The reason for this could be that a narrow mask opening prevents the arrival of ions and the diffusion of reaction products.

Subsequently, we tried deep RIE with a depth of more than $200 \mu \mathrm{m}$ using a $\mathrm{SF}_{6}$ etching gas with $5 \%$ oxygen. To increase the etch rate, the rf power to the sample stage was raised from 130 to $150 \mathrm{~W}$. The other etching conditions remained the same as they were in the previous experiments. Figure 5 shows the relationship between the etching time and etched depth. The similar relationship in case of $130 \mathrm{~W}$ rf stage power supply is also shown. The etched depths were calculated by subtracting the residual mask thickness, which was estimated from the $\mathrm{SiC}$ etching selectivity to the $\mathrm{Ni}$ mask, from the step height measured with the surface profiler. A $7 \mathrm{~h}$ etching yielded an etched depth of $216 \mu \mathrm{m}$. The etch rate reached $0.51 \mu \mathrm{m} / \mathrm{min}$, and the etching selectivity was 27.

Figures 6(a) and 6(b) show the cross-sectional SEM images of a sample etched for $7 \mathrm{~h}$, showing trenches with mask opening widths of $40-55$ and $170 \mu \mathrm{m}$, respectively. The mask opening with width of less than $100 \mu \mathrm{m}$ resulted in residue-free etching, whereas the wider mask opening generated spike-shaped residues on the etched bottom surface as shown in Fig. 6(b). The much wider mask opening with millimeter-order width also resulted in residue-free etching. The reason for this can be explained as follows. Reaction products from the etched bottom surface are partly evacuated from the trenches, and partly redeposit on the etched side walls. If the width of the trench increases, the amount of reaction products increases, but the capacity for redeposition on the etched side walls does not change considerably because the area of the etched side walls depends mainly on the length and depth of the trench, and the evacuation rate of the reaction products increases. In this experiment, there could be widths of the trench at which the above-mentioned three factors are balanced, and redeposition of the reaction products on the etched bottom surfaces may have occurred when the mask opening width was between the balanced widths. This redeposition can be avoided by increasing the pumping speed of the ME-ICP-RIE, raising the temperature of the substrates or gradually changing the etching conditions according to the etched depth. 


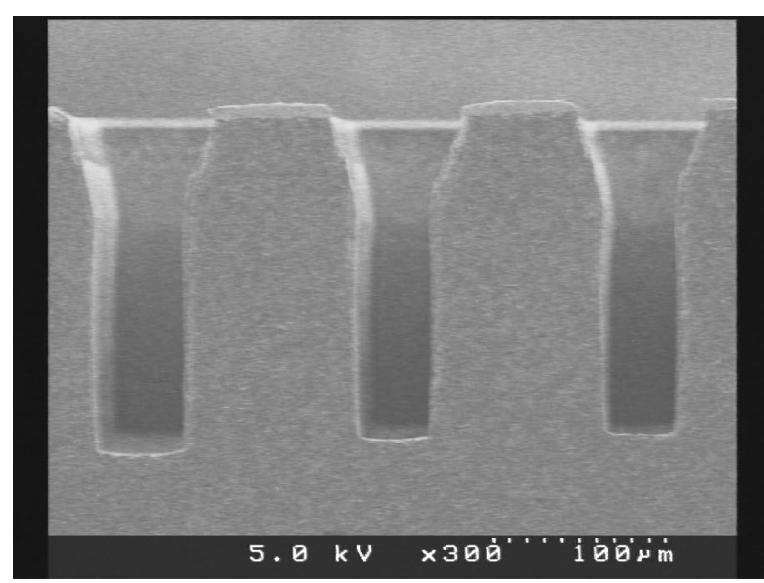

(a) Mask opening widths of 55, 40 and $40 \mu \mathrm{m}$ from the left.

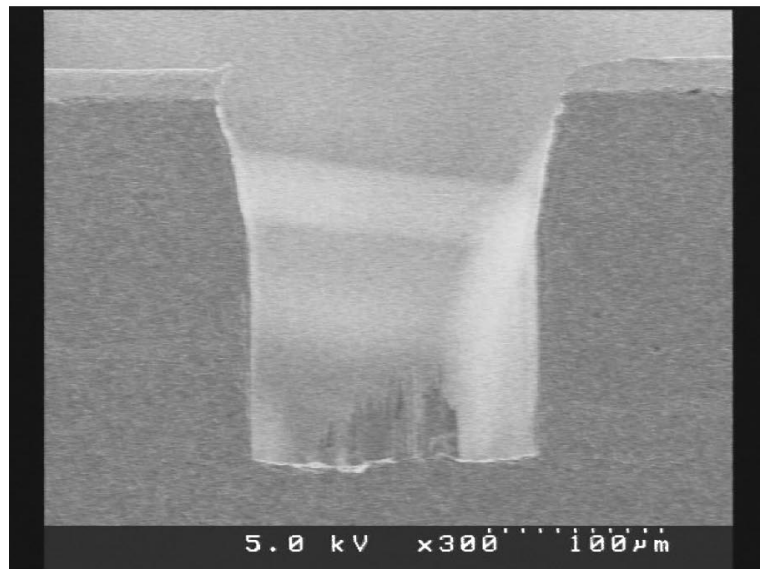

(b) Mask opening width of $170 \mu \mathrm{m}$.

FIG. 6. Cross-sectional SEM images of a sample etched for $7 \mathrm{~h}$.

Tapering of the upper parts of the trenches, as shown in Figs. 3 and 6, was caused mainly by the withdrawal of $\mathrm{Ni}$ mask edges during long periods of RIE. The surface roughness $(R a)$ at the 216- $\mu$ m-deep etched bottom surface was about $4500 \AA$. This large surface roughness could mainly be caused by grains of the sintered $\mathrm{SiC}$, which were produced from $\mathrm{SiC}$ powder with a mean diameter of about $0.7 \mu \mathrm{m}$.

\section{CONCLUSION}

We performed more than 100- $\mu$ m-deep reactive ion etching (RIE) of silicon carbide ( $\mathrm{SiC}$ ) for microelectromechanical systems used in harsh environments, where thermal resistivity or chemical inertness is required. We used a homemade magnetically enhanced, inductively coupled plasma reactive ion etcher, which enables high density plasma generation and high speed pumping. Sulfur hexafluoride mixed with oxygen was used as an etching gas and electroplated nickel was used as a mask. First, $5 \mathrm{~h}$ etching experiments using etching gases with $0 \%, 5 \%, 10 \%$, and $20 \%$ oxygen were performed by supplying rf power of 150 and $130 \mathrm{~W}$ to an ICP antenna and a sample stage, respectively. A maximum etch rate of $0.45 \mu \mathrm{m} / \mathrm{min}$ and a residuefree etched surface were obtained in the case of $5 \%$ oxygen addition. Observation of the cross sections of etched samples using a scanning electron microscope confirmed the microloading effect, which is reduction of the etched depth with a decrease in the mask opening width.

Next, a $7 \mathrm{~h}$ etching experiment using an etching gas with $5 \%$ oxygen was performed by increasing the rf power to the sample stage to $150 \mathrm{~W}$. This yielded an etched depth of 216 $\mu \mathrm{m}$. Mask openings with widths of less than $100 \mu \mathrm{m}$ and on the order of millimeters generated residue-free etched bottom surfaces even when their depth exceeded $200 \mu \mathrm{m}$. Deep RIE technology for $\mathrm{SiC}$ has the potential to open up new application areas for MEMS.

\section{ACKNOWLEDGMENTS}

This work was supported by The U.S. Air Force Office of Science Research. This work was also performed as part of Industrial Technology Research Grant Program in '00 sponsored by the New Energy and Industrial Technology Development Organization (NEDO) of Japan, and Regional Science Promoter Program sponsored by Iwate Techno Foundation under Japan Science and Technology Corporation (JST).

${ }^{1}$ R. S. Okojie, A. A. Ned, A. D. Kurtz, and W. N. Carr, Proceedings of the 9th IEEE International Conference on Microelectromechanical Systems, 1996, p. 146.

${ }^{2}$ A. Klumpp, U. Schaber, H. L. Offereins, K. Kühl, and H. Sandmaier, Sens. Actuators A 41-42, 310 (1994).

${ }^{3}$ A. A. Yasseen, C. A. Zorman, and M. Mehregany, J. Microelectromech. Syst. 8, 237 (1999).

${ }^{4}$ A. J. Fleischman, S. Roy, C. A. Zorman, M. Mehregany, and L. G. Matus, in Ref. 1, p. 236.

${ }^{5}$ A. A. Yasseen, C.-H. Wu, C. A. Zorman, and M. Mehregany, Proceedings of the 12th IEEE International Conference on Microelectromechanical Systems, 1999, p. 644.

${ }^{6}$ N. Rajan, M. Mehregany, C. A. Zorman, S. Stefanescu, and T. P. Kicher, J. Microelectromech. Syst. 8, 251 (1999).

${ }^{7}$ S. Tanaka, S. Sugimoto, J.-F. Li, R. Watanage, and M. Esashi, J. Microelectromech. Syst. 10, 55 (2001)

${ }^{8}$ J. Sugiura, W.-J. Lu, K. C. Cadien, and A. J. Steckl, J. Vac. Sci. Technol. B 4, 349 (1986).

${ }^{9}$ W.-S. Pan and A. J. Steckl, J. Electrochem. Soc. 137, 212 (1990).

${ }^{10}$ R. Padiyath, R. L. Wright, M. I. Chaudhry, and S. Babu, Appl. Phys. Lett. 58, 1053 (1991).

${ }^{11}$ P. H. Yih and A. J. Steckl, J. Electrochem. Soc. 140, 1813 (1993).

${ }^{12}$ P. H. Yih and A. J. Steckl, J. Electrochem. Soc. 142, 2853 (1995).

${ }^{13}$ W. Reichert, D. Stefan, E. Obermeier, and W. Wondrak, Mater. Sci. Eng., B 46, 190 (1997).

${ }^{14}$ C. Richter, K. Espertshuber, C. Wagner, M. Eickhoff, and G. Krötz, Mater. Sci. Eng., B 46, 160 (1997).

${ }^{15}$ A. J. Fleischman, C. A. Zorman, and M. Mehregany, J. Vac. Sci. Technol. B 16, 536 (1998).

${ }^{16}$ F. A. Khan and I. Adesida, Appl. Phys. Lett. 75, 15, 2268 (1999).

${ }^{17}$ J. S. Shor, A. G. Zhang, and R. M. Osgood, J. Electrochem. Soc. 139, 1213 (1992).

${ }^{18}$ J. S. Shor, R. M. Osgood, and A. D. Kurtz, Appl. Phys. Lett. 60, 1001 (1992).

${ }^{19}$ S. Kong, K. Minami, and M. Esashi, Trans. Inst. Electr. Eng. Jpn., Sect. E 117-E, 10 (1997).

${ }^{20}$ S. Wang, X. Li, K. Wakabayashi, and M. Esashi, J. Am. Ceram. Soc. 82, 1339 (1999).

${ }^{21}$ X. Li, T. Abe, and M. Esashi, Sens. Actuators A 87, 139 (2001).

${ }^{22}$ S.-K. Park, S.-W. Seo and S.-W. Rhee, Dry Etching of Tungsten Films Using $\mathrm{SF}_{6}$ and $\mathrm{SF}_{6} / \mathrm{O}_{2}$ Discharge, Proceedings of the Symposium on Highly Selective Dry Etching and Damage Control, Proc. 93-21 (The Electrochemical Society, Pennington, NJ, 1993), p. 243. 